\title{
Analysis and Forecasting the Agriculture Production Sector in
} Rwanda

\author{
Jean Niyigaba $^{1,2}$ \& Daiyan Peng ${ }^{1}$ \\ ${ }^{1}$ School of Economics, Huazhong University of Science and Technology, Wuhan, China \\ ${ }^{2}$ School of Economics, University of Rwanda, Kigali, Rwanda \\ Correspondence: Jean NIYIGABA, School of Economics, Huanzhong Univesity of Science and Technology, \\ 1037 Luoyu Road, Wuhan, 430074, P.R. China. E mail: niyigav@yahoo.fr
}

Received: May 5, 2020

Accepted: June 22, 2020

Online Published: July 10, 2020

doi:10.5539/ijef.v12n8p91

URL: https://doi.org/10.5539/ijef.v12n8p91

\begin{abstract}
Agriculture production is a crucial economic growth sector, especially for developing countries like Rwanda. Resulted from investments boosting in several areas, Rwanda experienced stable economic growth, where agriculture provides a vital contribution and significant Policies adopted for agriculture improvement. However, the sector's future development still unclear as it is manifesting decrement shares over the years in the county's economy and workforce. No research has yet projected the sector's future production to explain the sector's trend, allowing the government and partners to formulate strategies accordingly. This paper analyzes the sector's economic contribution over several years and forecasts its future. The useful combined grey model predicts the sector's production where a nonlinear grey Bernoulli model (NGBM) with an added optimal parameter (NGBM-OP) is used for the prediction after comparison to others. Outcomes in the sample size from 1960 to 2017, confirm the NGBM-OP as the reliable compared with other prediction models then becomes the best for forecast up to 2030. The obtained sector's production forecast, results pointed out the sector's slow production increment in the future. Suggest its improvement based on investment attractions, especially the young generation through financial facilitation, farmer's training, and opportunity awareness.
\end{abstract}

Keywords: forecasting, agriculture production, grey model

\section{Introduction}

The agriculture sector is crucial for sustainable development, and land areas are needed for agriculture crops as vital for humankind and economic growth, especially for developing countries like Rwanda. Land areas are under tension with other economic activities competing with the sector. Nowadays, farmers are required to produce more agriculture outputs on a small surface as urbanization is contracting farming lands (Hoque, 2020).

Apart from the developing countries like Rwanda, the developed also like New Zealand are facing the same issues, based on predominant agricultural outputs under pressure from both increased reactions from the concerned public and environmental limits. Successful transformation requires a proactive and flexible sectorial system that can fit new projects and approaches established by the infrastructural governance from the macro-level landscape (Wreford et al., 2019). In emerging nations, a raise in farming outputs involve sufficient food, and their limited resource will be used for other manufacturing areas imports (Alexander, 2012). However, it was recognized that farming production is limited by weak profitability and competitivity, especially for small farmers comparing with big-farms (Erokhin, 2017).

Rwanda is a developing nation experiencing stable economic growth recently, averaging $7.5 \%$ annually between 2000 and 2018. Higher than triple of Rwandan per capita GDP manifested from USD 211 to USD 718 in 2001-2014, and the rate of poverty reduced from 59\% to $39 \%$ in the same period. Furthermore, the agriculture sector is a fundamental economic component, offering around 30\% of the GDP and hiring around 70\% of the workforce (World Bank, 2019). Improvement policies adopted, including farming modernization, intensive agriculture, and professionalization (Maniriho, 2013). However, the sector contribution shares to the country's economy (GDP) are decreasing from 33\% to $28 \%$ in 2006-2019 (NISR, 2019). The rate of workers with low education levels increased, where the proportion of who completed the primary school and who not achieve any education levels increased from $70.7 \%$ to $92 \%$ in 2014-2017 (NISR, 2020). Employment proportion reduced 
from $88.6 \%$ to $69.8 \%$ in $2000-2017$, while young population involvement is at a low rate (NISR, 2020). Furthermore, in recent decays, malnutrition persists as a critical issue in the country, where $38 \%$ of under-five age children are suffering from stunting (NISR, 2015).

With the above, agriculture is perceived as one of the most influential for the country's sustainable development and strives against poverty. The sector's improvement policies contribute to its efficient structures. However, an enigma is how the improvement in the agricultural sector does not increase or maintain its economic contribution share, and why the sector's workforce rate, especially the knowledge workforce, is declining along the time. Furthermore, most of the research contributions are general theories. No specific analysis justifying if policy effort effects will be remarkable in the future, and no research made on the appropriated model for the sector's production forecasts. So that improved strategies and policies could be elaborated accordingly.

As the answer, this paper is descriptively analyzing the sector's trends and efficiently forecast its future production with an accurate model, considering the following aims:

- Descript, analyze, and interpret the Rwandan agriculture sector production trend and economic contribution;

- Precise the appropriate econometric prediction model and forecast the future sector production;

- Classify the existing weaknesses, strengths, and opportunities; then

- Propose sector's strategies for improvement.

This research applies descriptive data analysis, cointegration, and data in the grey prediction methods, from 1960 to 2017, and a forecast up to 2030. The grey prediction is used for different economic analyses and predictions and produced robust forecasts, even for limited sample size data. It is also adopted for complex series having obscure, doubtful, and uncontrolled structures (Julong, 2010). The same for Rwanda where the data series were also uncontrolled during the years 1972-1975, 1980-1990, 1990 to 1997 periods of internal conflicts, boosting rural area exodus for other economic activities in the large cities, and civil wars with the 1994 genocide, respectively (Uvin, 1996), (Lopez, 2005). With the identified method, the forecasting method is essential for accurate investment plans and policies in agriculture production. This univariate time-series method presents an approach, requiring just the variable historical data to forecast its future. Nevertheless, the significant observation numbers for forecasting accuracy is usually required.

The paper is fragmented as regards: Part 2 provides outlines of the material and methods, including descriptive analysis, ARIMA, GM, and NGBM-OP methods; Part 3 displays results, discussion, and results from prediction while the closing part compiles and concludes.

\section{Method}

This part depicts the agriculture production prediction model and its viability tests, while the data collected are from the National Institute of Statistics of Rwanda (NISR) publication reports and the World Bank dataset, as inTable 1. The timeframe study is from 1960 to 2017, and forecast up to 2030.

Grey models (GM) (Liu \& Lin, 2011) and the autoregressive integrated moving average (ARIMA) (George et al., 2016) techniques are compared where the more reliable is adopted for the forecast process. Reliability is shown by the one with the smallest mean absolute percentage error (MAPE), mean absolute error (MAE), and root mean square error (RMSE).

Nowadays, there are several kinds of forecasting methods, classified into two principal categories, quantitative and qualitative techniques. Qualitative techniques involve the prediction trend practice, the expert method, and many others. Quantitative techniques cover neural networks, linear and regression, genetic algorithm, time series, and Grey prediction method (Wen, 2004). Each method is suitable in selective applications.

The Grey system prediction approach adopted in this research was established by Deng in 1989. It is focusing on the analytical model relationship, model creation, and model events like discrete data, no confidence, multi-data, and insufficient data for forecasting and making the decision. Compared to various prediction methods, Grey methods were generally applied in several events predictions and produced robust forecasts. It is due to its adaptation even for limited sample size data and complex series having obscure, doubtful, and uncontrolled structures (Julong, 2010). It is in similar cases as the Rwandan situation, where data series were also uncontrolled during the years 1990 to 2000 periods of civil wars and the 1994 genocide. Despite that, some researches also realize specific weaknesses of the model, and improvements still can be enhanced (Lin \& Lee, 2007). Hence, to improve its prediction capacity and spread the grey method application range, researches provided various solutions. Several new varieties of grey models, like the generalized discrete grey model (GDGM), nonlinear grey Bernoulli model (NGBM) with an added suggestion of the NGBM optimal parameter 
model (NGBM-OP) and others were established following the $\operatorname{GM}(1,1)$ grey theory (Liu and Lin, 2011), (George et al., 2016), (Cheng et al., 2020). In this research the, nonlinear grey Bernoulli model (NGBM) with an optimal parameter model (NGBM-OP) was adopted based on its smallest values of MAE, RMSE, and MAPE compared with others in the study. As a robust system, the grey models estimated the future projections robustly in several areas, like engineering (Jiang et al., 2004), economics (Chen et al., 2008), and recently in the electronic paper industry and energy (Huang et al., 2015; Cheng et al., 2020). However, grey models, as others, do not have any control over future shocks or uncontrolled structures. All those performance and adjustments are being made on the past complex and uncontrolled structures. Analyses use the per capita variables, and 2010 as the base year, to avoid the population growth and currency depreciation effects respectively, and all values are in USD.

Table 1. Variables acronyms

\begin{tabular}{ll}
\hline Variable & Acronyms \\
\hline Per capita agriculture & $\mathrm{AGR}_{\mathrm{c}}$ \\
Per capita Gross capital formation (inverstiments) & $\mathrm{GCF}_{\mathrm{c}}$ \\
Per capita GDP & $\mathrm{GDP}_{\mathrm{c}}$ \\
\hline
\end{tabular}

\subsection{Models}

\subsubsection{ARIMA Prediction Model}

The Box-Jenkins model or autoregressive integrated moving average (ARIMA), is one of the statistical models that use the time series data to interpret the structure of data and forecast trends. It interprets and predicts a univariate time sequence following the linear aggregate of its past values and errors (George et al., 2016). ARIMA descriptions are organized in three steps: classification and estimate, diagnostics, and forecast. Its standards accept the stationary series, and this stationary necessity of a series is obtained after the first differentiation of originals. $\operatorname{ARIMA}(\mathrm{n}, \mathrm{d}, \mathrm{m})$, is represented as:

$$
\begin{gathered}
f_{n}(\mathrm{x})(1-\mathrm{x})^{d} Y_{t}=\delta+g_{m}(x) \mathrm{u}_{t} \\
f_{n}(\mathrm{x})=1-f_{1} x-f_{2} x^{2}-f_{3} x^{3}-\cdots \ldots \ldots \ldots \ldots-f_{n} x^{n} \\
g_{m}(\mathrm{x})=1-g_{1} x-g x^{2}-g x^{3}-\ldots \ldots \ldots \ldots \ldots-g_{m} x^{m}
\end{gathered}
$$

Where $Y_{t}$ the time sequence, $\mathrm{x}$ the backward turn driver, $\mathrm{d}$ the regular differentiation order, and ut arbitrary independent shocks. The sequence ut is recognized as a white noise method, where $\mathrm{fn}(\mathrm{x})$ and $\mathrm{gm}(\mathrm{x})$ are functions in $\mathrm{x}$, with $\mathrm{n}$ and $\mathrm{m}$ degrees, respectively.

\subsubsection{Grey Prediction}

The grey prediction is used for different predictions analyses and produced robust forecasts even for limited sample size data, and is also adopted for complex series having obscure, doubtful, and uncontrolled structures. Introduced by Julong (Julong, 2010). There are three prediction fundamental grey models processes: GM, AGO, and IAGO. Where GM: grey modeling, AGO: accumulated generating operation and IAGO: inverse accumulated generating operation. The usually GM $(1,1)$ type is adopted, where the first 1 designates the appearance of just one variable, while the following 1 indicates the grey equation in the first-order differential. The GM $(1,1)$ is represented as:

$$
\text { Let }, X^{(0)}=\left[x^{(0)}(0), x^{(0)}(1), x^{(0)}(2), x^{(0)}(3) \ldots \ldots \ldots \ldots \ldots \ldots x^{(0)}(m)\right]
$$

the raw data sequence where $\mathrm{m} \geq 3$.

1) Take $X^{(0)}$ AGO of Equation (2)

$$
\begin{aligned}
& X^{(1)}= {\left[x^{(1)}(1), x^{(1)}(2), x^{(1)}(3), x^{(1)}(4) \ldots, x^{(1)}(k), \ldots \ldots, x^{(1)}(m)\right] } \\
& \text { Where } x^{(1)}(\mathrm{k})=\mathrm{AGO} x^{(0)}(k)=\sum_{i=1}^{k} x^{(0)}(i) \\
& Y^{(1)}=\left[y^{(1)}(1), y^{(1)}(2), y^{(1)}(3), y^{(1)}(4), \ldots \ldots, y^{(1)}(k), \ldots y^{(1)}(m)\right]
\end{aligned}
$$

2) Let, Equation (5) be the sequence made from $X^{(1)}$ by the neighbor adjacent means. With $k=1,2 \ldots \mathrm{m}$; we express $\mathrm{y}^{(1)}(\mathrm{k})$ in $\left.\mathrm{x}^{(0)} \mathrm{k}\right)$ :

$$
\begin{gathered}
y^{(1)}(\mathrm{k})=\frac{1}{2}\left[x^{(1)}(k-1)+x^{(1)}(\mathrm{k})\right] \\
\text { Thus: } a y^{(1)}(k)+x^{(0)}(k)=b
\end{gathered}
$$


is the basic form of GM $(1,1)$ model. "a" is the develop parameter, "b" the grey input.

3) OLS method is used to find [a b]T

With a non-negative $\mathrm{X}^{(0)}$;

$$
\text { If }\left[\begin{array}{l}
a \\
b
\end{array}\right]=\left(\mathrm{B}^{T} \mathrm{~B}\right)^{-1} \mathrm{~B}^{T} A_{N}
$$

is a parameters series, and

$$
A=\left[\begin{array}{c}
x^{(0)}(1) \\
x^{(0)}(2) \\
\cdot \\
\cdot \\
x^{(0)}(m)
\end{array}\right], B=\left[\begin{array}{cc}
-y^{(1)}(1) & 1 \\
-y^{(1)}(2) & 1 \\
\cdot & \cdot \\
-y^{(1)}(m) & 1
\end{array}\right]
$$

$$
\text { Let, } \frac{d \hat{x}^{(1)}}{d t}+a \hat{\mathbf{x}}^{(1)}=b \text { be the model whitenization or image; }
$$

Thus, the whitenization solution or time response function is given by:

$$
\begin{aligned}
\hat{\mathrm{x}}^{(1)}(k) & =e^{-a k}\left[-\frac{b}{a}+x^{(1)}(0)\right]+\frac{b}{a} \\
\text { And } \hat{\mathrm{x}}^{(1)}(k) & =e^{-a k}\left[-\frac{b}{a}+x^{(0)}(0)\right]+\frac{b}{a}
\end{aligned}
$$

The predicted value of $\hat{\mathrm{x}}^{(0)}(\mathrm{k}+1)$ with IAGO on $\hat{\mathrm{x}}^{(1)}(\mathrm{k}+1)$, is:

$$
\begin{gathered}
\hat{\mathrm{x}}^{(1)}(k)=\left[x^{(0)}(0)-\frac{b}{a}\right] e^{-a k}+\frac{b}{a} \\
\hat{\mathrm{x}}^{(0)}(\mathrm{k}+1)=\hat{\mathrm{x}}^{(1)}(\mathrm{k}+1)-\hat{\mathrm{x}}^{(1)}(\mathrm{k}) \\
\hat{\mathrm{x}}^{(0)}(\mathrm{k}+1)=\left(1-\mathrm{e}^{\mathrm{a}}\right) e^{-a(k+1)}\left[x^{(0)}(0)-\frac{b}{a}\right]
\end{gathered}
$$

Where parameters "a" and "b" in the GM $(1,1)$, are the development coefficients and grey action quantities, respectively. Expressed as:

$$
\begin{gathered}
a=\frac{\sum_{k=1}^{m} y^{(1)}(k) \sum_{k=1}^{m} x^{(0)}(k)-(m-1) \sum_{k=1}^{m} x^{(0)}(k) y^{(1)}(k)}{(m-1) \sum_{k=1}^{m}\left[y^{(1)}(k)\right]^{2}-\left[\sum_{k=1}^{m} y^{(1)}(k)\right]^{2}} \\
b=\frac{\sum_{k=1}^{m} x^{(0)}(k) \sum_{k=1}^{m}\left[y^{(1)}\right]^{(2)}-\sum_{1}^{m} y^{(1)}(k) \sum_{1}^{m} x^{(0)}(k) y^{(1)}(k)}{\left.(m-1) \sum_{k=1}^{m} y(k)\right]^{2}-\left[\sum_{k=1}^{n} y^{(1)}(k)\right]^{2}}
\end{gathered}
$$

Where $\left[\hat{\mathrm{x}}^{(0)}(0), \hat{\mathrm{x}}^{(0)}(1) \ldots, \hat{\mathrm{x}}^{(0)}(\mathrm{k}), \ldots \ldots . ., \hat{\mathrm{x}}^{(0)}(\mathrm{m})\right]$, are the fitted $\operatorname{GM}(1,1)$ series.

\subsubsection{Nonlinear Grey Bernoulli with Optimal Parameter Model (NGBM-OP) Prediction Method}

The NGBM-OP is also written as $\mathrm{NGBM}^{\mathrm{n}}$, Where $\mathrm{n}$ is the optimum prediction parameter. The accumulated generating operation (AGO) method was implemented in the grey model for the raw data minimum randomization. Meanwhile, the grey prediction is combining with other delicate computing methods for more prediction accuracy. This research adopts an adjustment of the GM with an introduction of the differential equation theory to improve that ability prediction precision. Following the nonlinear differential Bernoulli equation, the procedures derive on the NGBM as follows:

Where

$$
\begin{gathered}
a y^{(1)}(k)+x^{(0)}(k)=b\left[z^{(1)}(k)\right]^{n}, n \in \mathbb{R} \\
y^{(1)}(\mathrm{k})=0.5\left[x^{(1)}(\mathrm{k}-1)+x^{(1)}(k)\right]
\end{gathered}
$$

The MAPE defines the optimal value of $\mathrm{n}$ in the model. Following the ordinary differential equation approach with one adjustable variable (Dennis, 2018), from Equation (10); a related nonlinear Bernoulli differential equation form is established as:

Then the $\mathrm{NGBM}^{\mathrm{n}}$ parameters are

$$
\frac{d \hat{\mathrm{x}}^{(1)}}{d t}+a \hat{\mathrm{x}}^{(1)}=b\left[\hat{\mathrm{x}}^{(1)}\right]^{n}
$$

$$
\left[\begin{array}{l}
a \\
b
\end{array}\right]=\left(\mathrm{B}^{T} \mathrm{~B}\right)^{-1} \mathrm{~B}^{T} A_{N}
$$




$$
\text { Where } A=\left[\begin{array}{c}
x^{(0)}(1) \\
x^{(0)}(2) \\
\cdot \\
\cdot \\
x^{(0)}(m)
\end{array}\right] \text {, and } B=\left[\begin{array}{ccc}
-y^{(1)}(1) & {\left[y^{(1)}(2)\right]^{n}} & 1 \\
-y^{(1)}(2) & {\left[y^{(1)}(3)\right]^{n}} & 1 \\
\cdot & \cdot & \\
\cdot & \cdot & \\
-y^{(1)}(m) & {\left[y^{(1)}(m)\right]^{n}} & 1
\end{array}\right]
$$

With OLS a and $\mathrm{b}$ are calculated as:

$$
\begin{aligned}
& a=\frac{\sum_{k=2}^{m}\left\{\left[y^{(1)}(k)\right]^{n} x^{(0)}(k)\right\} \sum_{k=1}^{m}\left[y^{(1)}(k)\right]^{n+1}-\sum_{k=1}^{m} y^{(1)}(k) x^{(0)}(k) \sum_{k=1}^{m}\left[y^{(1)}(k)\right]^{2 n}}{\sum_{1}^{m}\left[y^{(1)}(k)\right]^{2} \sum_{k=1}^{m}\left[y^{(1)}(k)\right]^{2 n}-\left\{\sum_{k=1}^{m}\left[y^{(1)}(k)\right]^{n+1}\right\}^{2}} \\
& b=\frac{\sum_{k=1}^{m}\left[y^{(1)}(k)\right]^{2} \sum_{k=1}^{m}\left\{x^{(0)}(k)\left[y^{(1)}(k)\right]^{n}\right\}-\sum_{2}^{m}\left[y^{(1)}(k)\right]^{n+1} \sum_{k=1}^{m} y^{(1)}(k) x^{(0)}(k)}{\sum_{1}^{m}\left[y^{(1)}(k)\right]^{2} \sum_{k=1}^{m}\left[y^{(1)}(k)\right]^{2 n}-\left\{\sum_{k=1}^{m}\left[y^{(1)}(k)\right]^{n+1}\right\}^{2}}
\end{aligned}
$$

The identical solution of Equation (19) is:

$$
\hat{\mathrm{x}}^{(1)}(k)=\left\{\frac{b}{a}+\left[-\frac{b}{a}+x^{(0)}(0)^{(1-n)}\right] e^{-a(1-n) k}\right\}^{1 /(1-n)}
$$

Forecasting efficiency is done by assessing three distinct statistical values: the MAE: mean absolute error, RMSE: root mean square error and the MAPE: mean absolute percentage error as follows:

$$
M A E=\sum_{k=1}^{m}\left|P_{k}-A_{k}\right| / m, R M S E=\sqrt{\sum_{k=1}^{m}\left(P_{k}-A_{k}\right)^{2} / m} \text {, and MAPE }=\frac{\sum_{k=1}^{m}\left|\left(P_{k}-A_{k}\right) / A_{k}\right|}{m} * 100
$$

Where $\mathrm{P}_{\mathrm{k}}$ and $\mathrm{A}_{\mathrm{k}}$ are the forecasted $\mathrm{k}^{\text {th }}$, and original values, sequentially, and $\mathrm{m}$ the whole prediction numbers. As (Lewis, 1982), the MAPE results assess the forecast efficiency, where above $50 \%$ is inaccurate, $20 \%$ to $50 \%$ is reasonable, $10 \%$ to $20 \%$ is good, and lower than $10 \%$ is highly accurate.

\section{Results}

From 1960 to 2017, at a constant base year 2010 in US\$, variables summary is as in Table 2, Table 3 and Table 4, while several plots for the agriculture stector are as in Figure 1, Figure 2, and Figure 3.

\subsection{Descriptive Analyis}

\begin{tabular}{|c|c|c|c|c|c|c|}
\hline Proportions $\%$ & 2002 & 2006 & 2010 & 2014 & 2018 & Average \\
\hline employment & 86.6 & 79 & 72.5 & 67.6 & 69.8 & 75.1 \\
\hline \multicolumn{7}{|l|}{ Highest level of education } \\
\hline Education & 2002 & 2006 & 2010 & 2014 & 2018 & Average \\
\hline Primary \& none & 96.1 & 96.5 & 96.5 & 90.1 & 94.4 & 94.72 \\
\hline Post primary & 2.3 & 1.8 & 1.1 & 7 & 5.3 & 3.50 \\
\hline Secondary \& vocational & 1.6 & 1.5 & 2.1 & 2.7 & 0.3 & 1.64 \\
\hline University & 0 & 0.1 & 0.2 & 0.2 & 0.0 & 0.10 \\
\hline Unknown & 0 & 0.1 & 0.1 & 0 & 0 & 0.04 \\
\hline Total & 100 & 100 & 100 & 100 & 100 & 100 \\
\hline \multicolumn{7}{|l|}{ Age group } \\
\hline Age group & $25-34$ & $35-44$ & $45-54$ & $55-64$ & $65+$ & average \\
\hline percentages & 64.2 & 68.4 & 78.1 & 85.1 & 92.0 & 75.1 \\
\hline
\end{tabular}

Table 2. Economic contribution proportion by sector from 2006 to 2018

\begin{tabular}{lcccccccccccccc}
\hline Sector's shares (\%) & 2006 & 2007 & 2008 & 2009 & 2010 & 2011 & 2012 & 2013 & 2014 & 2015 & 2016 & 2017 & 2018 & Average \\
\hline Agriculture & 33 & 29 & 29 & 29 & 28 & 28 & 29 & 28 & 28 & 28 & 30 & 30 & 28 & 29 \\
industry & 16 & 16 & 15 & 15 & 17 & 18 & 18 & 17 & 17 & 17 & 16 & 16 & 17 & 16.5 \\
services & 44 & 48 & 48 & 49 & 47 & 47 & 47 & 48 & 48 & 48 & 47 & 47 & 48 & 47.4 \\
Taxes & 7 & 7 & 8 & 7 & 8 & 7 & 6 & 7 & 7 & 7 & 7 & 7 & 7 & 7.1 \\
Total & 100 & 100 & 100 & 100 & 100 & 100 & 100 & 100 & 100 & 100 & 100 & 100 & 100 & 100 \\
\hline
\end{tabular}

Source: National institute of statistics of Rwanda (NISR) and author.

Table 3. Agriculture proportion employment, education levels, and age group from 2002 to 2018

Source: NISR and author calculations. 
Rwandan agriculture is among the principal economic components, offered on average 29\% of the GDP, and hired $75.1 \%$ of the workforce on average from 2006 to 2018, as displayed in Table 2 and Table 3. However, Figure 1 demonstrates how its contribution shares to the country's economy (GDP) decreased from 33\% in 2006 to $28 \%$ in 2018 , while the population proportion of employed in the sector reduced from $88.6 \%$ in 2002 to $69.8 \%$ in 2018. Furthermore, the sector involvement contains a high rate of the elderly population with a low level of education, as in Figure 2.

Table 4. Agrc, GDPc, and GCFc descriptive statistics from 1960 to 2017

\begin{tabular}{llll}
\hline Variables in USD & AGRc & GDPc & GCFc \\
\hline Standard deviation & 31.44 & 124.41 & 56.27 \\
Mean & 120.87 & 400.99 & 58.91 \\
Coefficient of variation CV (\%) & 26.02 & 31.03 & 95.53 \\
Compound annual growth rate (CAGR) & CAGRc & CAGRc & CAGR \\
{$[1960-1970[$} & $-0.19 \%$ & $-0.14 \%$ & $0.77 \%$ \\
{$[1970-1980[$} & $3.34 \%$ & $1.60 \%$ & $7.53 \%$ \\
{$[1980-1990[$} & $-2.66 \%$ & $-1.13 \%$ & $1.60 \%$ \\
{$[1990-2000[$} & $2.41 \%$ & $-1.20 \%$ & $1.95 \%$ \\
{$[2000-2007]$} & $2.28 \%$ & $4.96 \%$ & $9.12 \%$ \\
] $2007-2017]$ & $2.53 \%$ & $3.91 \%$ & $6.32 \%$ \\
General CAGRc & $1.28 \%$ & $1.45 \%$ & $5.38 \%$ \\
\hline
\end{tabular}

Source: author's calculations.

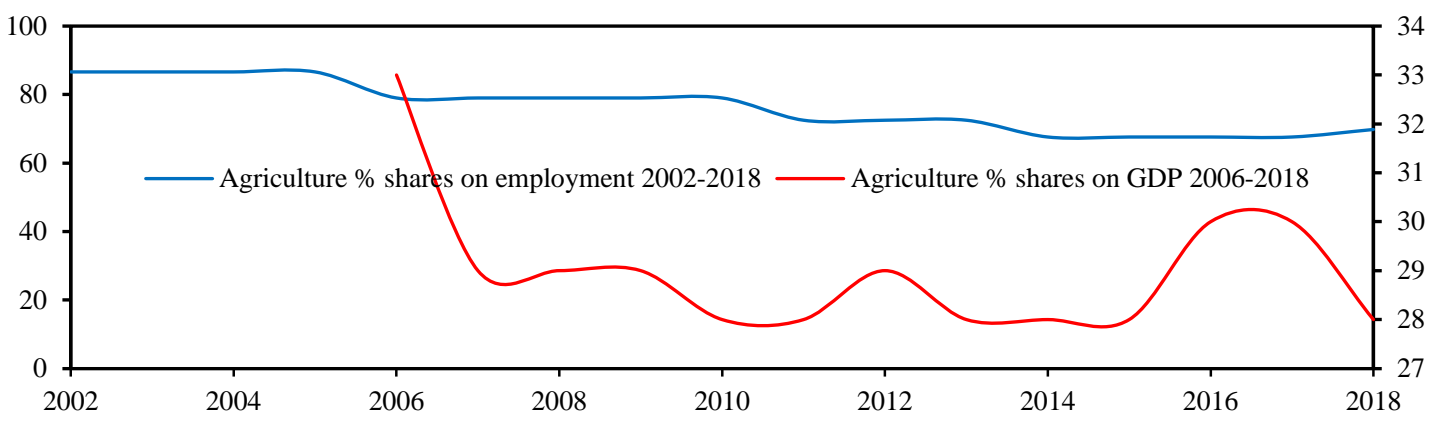

Figure 1. Agriculture shares, on employment and GDP

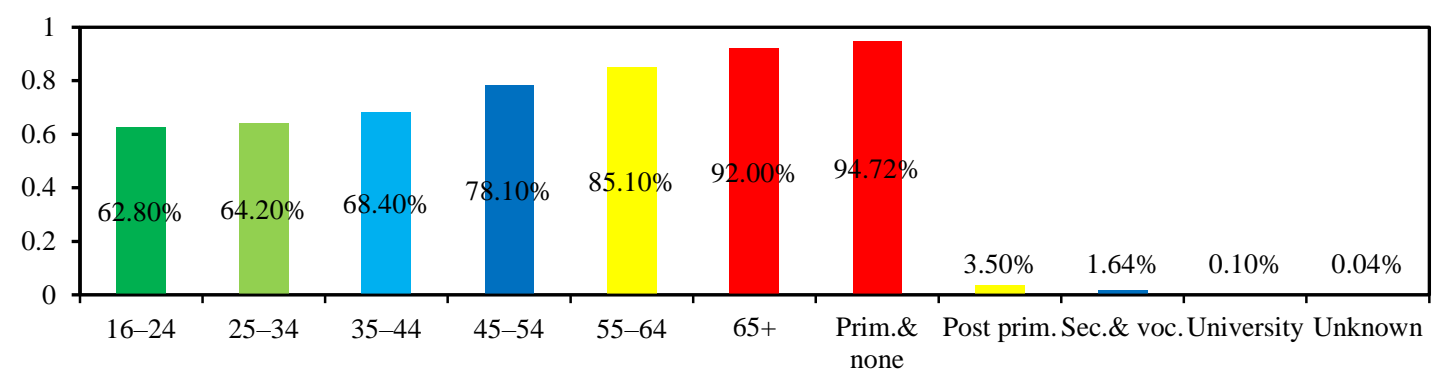

Figure 2. Agriculture employment age and education level proportions

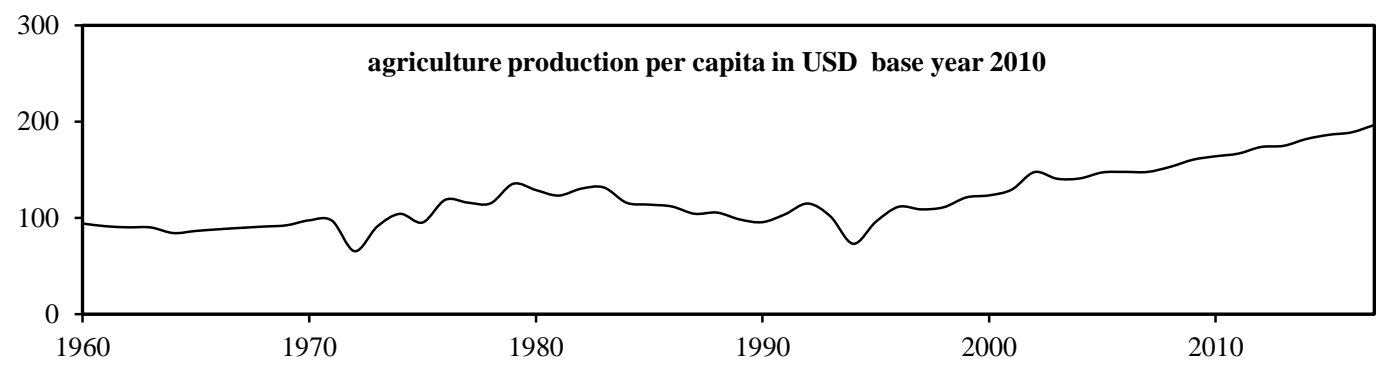

Figure 3. Per capita agriculture production time series plot $1960-2017$ 
Figure 3 displays the per capita agriculture production time series from 1960 to 2017 with exogenous uncontrolled chocks on the Rwandan agriculture production trend. Resulted from the years 1972-1975, 1980-1990, 1990 to 1997 periods of internal conflicts, boosting rural area exodus for other economic activities in the large cities, and civil wars with the 1994 genocide, respectively (Uvin, 1996), (Lopez, 2005).

\subsection{Forecasting}

The NGBM-OP $(1,1)$ method is compared with the GM $(1,1)$ and ARIMA $(3,1,2)$ methods applying original data from 1960 to 2017. The sample is adopted to estimate the RMSE, MAE, and MAPE then decide the reliable model for forecast efficiency as in Table 5. The smallest MAPE determines the most reliable grey model, applied to develop the best $\mathrm{NGBM}^{\mathrm{n}}$ according to the reliable parameter $\mathrm{n}$. Optimum Parameter $\mathrm{n}$ is defined by the digital iterative process using the values of MAPE. The below figure presents various MAPEs in the NGBM results, with 0.01 of $n$ increments set from -0.2 to 0.2 . All practical optimization algorithm tests approve the optimum $n$ equal to -0.1 as it gives the smallest MAPE value in the NGBM-OP. Parameters a and $b$ values of NGBM-OP $(1,1)$ and $\mathrm{GM}(1,1)$ are displayed in Table 6.

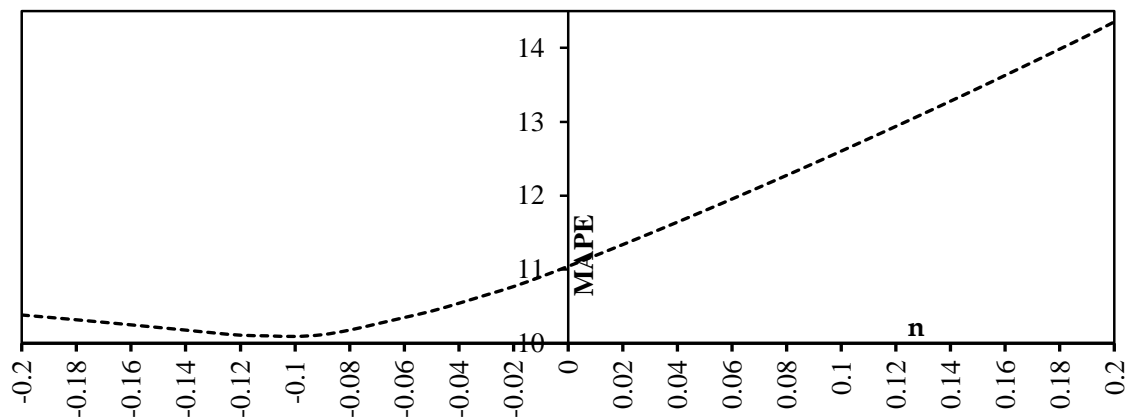

Figure 4. Per capita agriculture MAPEs with various power $n$ in $\operatorname{NGBM}^{\mathrm{n}}(1,1)$

Table 5. ARIMA $(3,1,2)$, GM $(1,1)$ and NGBM-OP $(1,1)$ comparisons

\begin{tabular}{llll}
\hline \multicolumn{2}{l}{ Agriculture Prediction efficiency Parameters } & & \\
\hline MAE & ARIMA(3,1,2) & GM(1,1) & NGBM $^{\mathrm{n}}-\mathrm{OP}(1,1), \mathrm{n}=-0.1$ \\
RMSE & 18.1499 & 12.2366 & 11.2256 \\
MAPE & 23.6400 & 15.9843 & 15.3428 \\
\hline
\end{tabular}

Source: author calculations.

Table 6. GM $(1,1)$ and $\operatorname{NGBM}^{\mathrm{n}}(1,1)$ a and $\mathrm{b}$

\begin{tabular}{lll}
\hline Parameters & GM & NGBM $^{\mathrm{n}}$, where $\mathrm{n}=-0.1$ \\
\hline $\mathrm{a}$ & -0.0138 & -0.0168 \\
$\mathrm{~b}$ & 78.1086 & 148.8390 \\
\hline
\end{tabular}

Source: author calculations.

Table 5 Forecast efficiency remarks are as the following: first, the NGBM-OP is with the a good forecast accuracy (Lewis, 1982), as its MAPE, MAE, and RMSE values are the lowest equal to 10.09\%, 11.23, and 15.34, respectively compared with those for $\operatorname{ARIMA}(3,1,2)$ and $\mathrm{GM}(1,1)$. Second, Figure 4 reveals the advanced digital iterative approach with an adequate algorithm to decide the optimal parameter $\mathrm{n}$. Third, the introduced iterative process is a useful algorithm for parameter $\mathrm{n}$ extraction in the NGBM-OP for the model efficiency enhancement. The optimal parameter $\mathrm{n}$ is -0.1 , and the GM parameters $\mathrm{a}$, and $\mathrm{b}$ are displayed in Table 6 .

The predictions presented in Table 7 present some discrepancies with the real data observed in the past; this was due to the uncontrolled chocks on the Rwandan agriculture trend as other economic and social areas. Resulted from the years 1972-1975, 1980-1990, 1990 to 1997 periods of internal conflicts, boosting rural area exodus for other economic activities in the large cities, and civil wars with the 1994 genocide, respectively (Uvin, 1996), (Lopez, 2005). However, the MAPE, MAE, and RMSE interval errors values equal to 10.09\%, 11.23, and 15.34, respectively, are acceptable and considered to produce a good forecast efficiency according to the previous researches (Lewis, 1982). 
Table 7. Agr $_{\mathrm{c}}$ production forecast to 2030

\begin{tabular}{|c|c|c|c|c|c|}
\hline \multirow{2}{*}{ Year } & \multicolumn{2}{|c|}{ Production in USD } & \multirow{2}{*}{ Year } & \multicolumn{2}{|c|}{ Production in USD } \\
\hline & Actual & NGBM & & Actual & NGBM \\
\hline 1960 & 94.24 & 94.24 & 1996 & 111.59 & 128.12 \\
\hline 1961 & 91.46 & 93.28 & 1997 & 108.94 & 130.07 \\
\hline 1962 & 90.30 & 90.27 & 1998 & 111.16 & 132.05 \\
\hline 1963 & 90.20 & 88.98 & 1999 & 121.38 & 134.07 \\
\hline 1964 & 84.35 & 88.45 & 2000 & 123.46 & 136.13 \\
\hline 1965 & 86.57 & 88.36 & 2001 & 129.45 & 138.23 \\
\hline 1966 & 88.30 & 88.55 & 2002 & 147.65 & 140.37 \\
\hline 1967 & 89.77 & 88.94 & 2003 & 140.74 & 142.55 \\
\hline 1968 & 91.10 & 89.48 & 2004 & 141.05 & 144.77 \\
\hline 1969 & 92.42 & 90.15 & 2005 & 147.30 & 147.04 \\
\hline 1970 & 97.59 & 90.91 & 2006 & 147.84 & 149.34 \\
\hline 1971 & 97.24 & 91.75 & 2007 & 147.82 & 151.68 \\
\hline 1972 & 65.49 & 92.67 & 2008 & 153.13 & 154.07 \\
\hline 1973 & 91.12 & 93.65 & 2009 & 160.51 & 156.50 \\
\hline 1974 & 104.31 & 94.70 & 2010 & 164.08 & 158.98 \\
\hline 1975 & 95.32 & 95.79 & 2011 & 166.82 & 161.50 \\
\hline 1976 & 118.84 & 96.93 & 2012 & 173.70 & 164.06 \\
\hline 1977 & 115.92 & 98.13 & 2013 & 174.92 & 166.67 \\
\hline 1978 & 115.23 & 99.36 & 2014 & 181.98 & 169.33 \\
\hline 1979 & 135.53 & 100.64 & 2015 & 186.36 & 172.03 \\
\hline 1980 & 128.99 & 101.96 & 2016 & 188.92 & 174.78 \\
\hline 1981 & 123.24 & 103.32 & 2017 & 196.55 & 177.59 \\
\hline 1982 & 130.43 & 104.71 & 2018 & & 180.44 \\
\hline 1983 & 131.70 & 106.15 & 2019 & & 183.34 \\
\hline 1984 & 115.84 & 107.62 & 2020 & & 186.29 \\
\hline 1985 & 113.88 & 109.13 & 2021 & & 189.29 \\
\hline 1986 & 111.93 & 110.67 & 2022 & & 192.35 \\
\hline 1987 & 104.38 & 112.25 & 2023 & & 195.45 \\
\hline 1988 & 105.58 & 113.87 & 2024 & & 198.62 \\
\hline 1989 & 98.47 & 115.53 & 2025 & & 201.84 \\
\hline 1990 & 95.69 & 117.22 & 2026 & & 205.11 \\
\hline 1991 & 103.88 & 118.94 & 2027 & & 208.44 \\
\hline 1992 & 114.99 & 120.70 & 2028 & & 211.83 \\
\hline 1993 & 101.62 & 122.50 & 2029 & & 215.28 \\
\hline 1994 & 73.22 & 124.34 & 2030 & & 218.79 \\
\hline 1995 & 95.99 & 126.21 & & & \\
\hline
\end{tabular}

Source: World Bank dataset and author calculations.

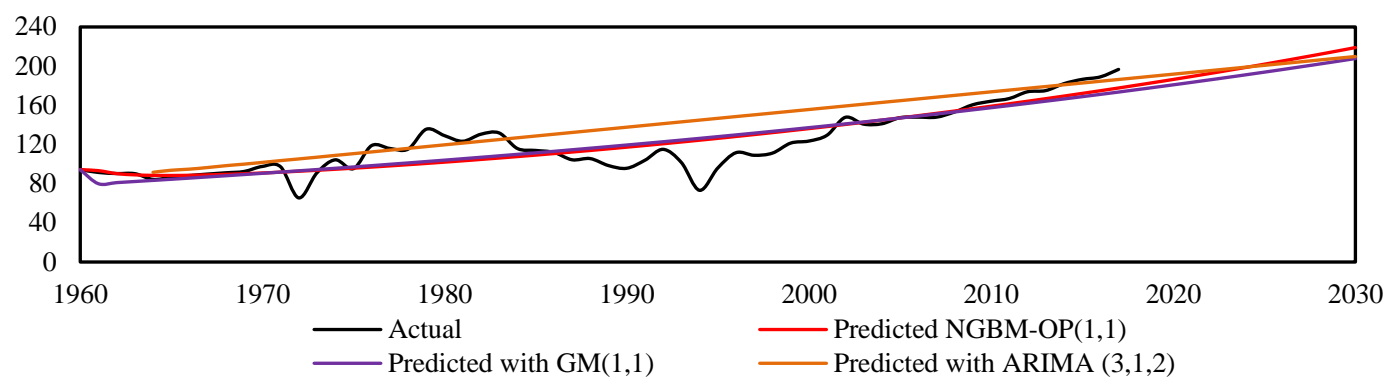

Figure 5. Per capita agriculture original and forecast plots to 2030

\section{Discussion}

This research collects 1960 to 2017 annual time series Rwandan variables from the World Bank dataset 2018 and other complement data from the National institute of statistics of Rwanda (NISR) as the summary displayed inTable 2, Table 3, and Table 4. The results as in show that Rwandan agriculture is among the principal economic components, offered on average $29 \%$ of the GDP, and hired $75.1 \%$ of the workforce on average from 2006 to 2018 , as displayed in the result's summary and previous researchers. However, Figure 1 demonstrates how its contribution shares to the country's economy (GDP) decreased from 33\% in 2006 to $28 \%$ in 2018, while the 
population proportion of employed in the sector reduced from $88.6 \%$ in 2002 to $69.8 \%$ in 2018 . Furthermore as in Figure 2, the sector involvement contains also a high rate of the elderly population with a low level of education.

The GCFc is with a high coefficient of variation (CV) equal to $95.53 \%$, greater than 50\%, indicating the Rwandan investment boosting in different sectors since 1960 . While the agriculture sector coefficient of variation is not only under $50 \%$ with $26.02 \%$, but also less than the average economic growth $\mathrm{CV}$ of $31.3 \%$, indicating a non-significant change in the sector production performance.

With the forecasting method to predict the Rwandan agriculture production up to 2030, the applied procedure covers three methods, ARIMA, GM, and NGBM-OP, where the NGBM-OP is the most faithful with the lowest MAPE, RMSE, and MAE. The forecast shows that in the coming ten years ]2017-2027], agriculture will rise at a compound annual growth rate (CAGR) of 1.45\%, lower than the CAGR of the past ten years ]2007-2017], which was $2.53 \%$, indicating a resource switching scenario to other areas rather than agriculture in this prediction period.

The forecasting results also are compared to preceding forecasting researchers (Wang et al., 2011), and (Lee and Tong, 2011). Wang et al., through the period 2006-2010, their MAPE scale from $1.28 \%$ to $14.52 \%$, and their revised discrete grey model (RDDM) had the most reliable forecasting accuracy with MAPE $=1.28 \%$. Tong and Lee introduced an enhanced forecasting grey model combining residual adjustment with ancestral programming sign estimate to forecast the China energy consumption, and the MAPE was $20.23 \%$. Therefore, following Lewis's rules and preceding studies, this research NGBM-OP reveals a good forecast for Rwandan agriculture production. The predicted MAPE value is $10.09 \%$, approximating Lewis's criteria, of 10\%(Lewis, 1982). Nevertheless, with the upgraded agriculture and social structure, it is advised to refresh the results every one or two years to get further specific results.

\section{Conclusion}

According to the research aims, agriculture sector production contributes significantly to the country's economy while investments are boosting in different country's economic sectors. The government improved several policies adopted in the agriculture sector, including farming modernization, intensive agriculture, and professionalization (Maniriho, Bizoza, 2013). However, the agriculture sector requirements to operate at a reliable status, including investments, workforce, young population, and skills, are still at an inadequate level. Its contribution shares to the country's economy (GDP), and a competent workforce supports the statement. Where its share to GDP decreased from $33 \%$ to $28 \%$ in 2006-2018, and the employed proportion reduced from $88.6 \%$ to $69.8 \%$ in 2002-2018, involving a high elderly population rate with low education level. The forecasting also proves that, despite the prediction increment of the sector production in general, this increment is at the flat rate compared to the previous years. Thus based on the research goals, results, and previous literature findings, the agriculture sector is among the key Rwandan economy contributor. However, the sector still at low production capability with no sufficient investors, the population workforce is abdicating (leaving) the sector, especially the young generation, and the high rate of the remained in the industry is the elderly population with a low level of education.

With the research purpose and results obtained, the government and partners in the sector should support the agriculture sector's emergence towards a sustainable status. With many transformation strategies, including investment promotion, by more investment attractions, especially the young generation through financial facilitation, intensify the appropriated farmer's training to overcome the skills gaps identified, and awareness of the sector's opportunities.

This research was able to indicate the predication staus of the sector with the past and current scenarios, and identify the issues existing in the industry. Including the sector's workforce abdication, inadequate investments, elder population rate, and low-level skills in the industry, then propose some measures to overcome those issues. Despite that, findings could not identify if the Rwandan agriculture land-use sector with the scenarios could remain economically competitive with other economic activities land-use sectors. It neither captures the reasons for agriculture workforce abdication nor the reasons for staying with a high rate of the old population and a low level of education. However, such fine-grained research goes beyond the scope of this paper and provides a research line for further studies.

\section{References}

Alexander, M. (2012). An econometric analysis of the relationship between agricultural Production and economic growth in Zimbabwe. Russ. J. Agric., 11, 16-23. https://doi.org/10.18551/rjoas.2013-11.02

Chen, C., Long, H., \& Chen, S. (2008). Forecasting of foreign exchange rates of Taiwan's major trading partners by novel nonlinear grey Bernoulli model NGBM (1, 1). Sci. Direct, 13, 1194-1204. https://doi.org/10.1016/j.cnsns.2006.08.008 
Cheng, M., Li, J., Liu, Y., \& Liu, B. (2020). Forecasting clean energy consumption in China by 2025: Using improved grey model GM (1, N). Sustain., 12, 1-20. https://doi.org/10.3390/su12020698

Dennis, G. Z. (2018). Advanced Engineering Mathematics. Loyola Marymount University., Jones \& Bartlett Learning.

Erokhin, V. (2017). Factors influencing food markets in developing countries: An approach to assess sustainability of the food supply in Russia. Sustainability, 9, 1313. https://doi.org/10.3390/su9081313

George, E., Jenkins, G., Gregory, R., \& Greta, L. (2016). Time series analysis, forecasting and control (5th ed.). John Wiley \& Sons, Inc., Hoboken, New Jersey.

Hoque. (2020). Future Impact of Land Use/Land Cover Changes on Ecosystem Services in the Lower Meghna River Estuary, Bangladesh. Sustainability, 12, 2112. https://doi.org/10.3390/su12052112

Huang, Y., Wang, C., Dang, H., \& Lai, S. (2015). Predicting the Trend of Taiwan's Electronic Paper Industry by an Effective Combined Grey Model. Sustainability, 7, 10664-10683. https://doi.org/10.3390/su70810664

Jiang, Y., Yao, Y., Deng, S., \& Ma, Z. (2004). Applying grey forecasting to predicting the operating energy performance of air cooled water chillers. International Journal of Refrigeration, 27(4), 385-392. https://doi.org/10.1016/j.ijrefrig.2003.12.001

Julong, D. (2010). Introduction to grey systems theory. J. Grey Syst. Syst., 1, 1-24. https://doi.org/10.1007/978-3-642-16158-2_1

Lee, Y. S., \& Tong, L. I. (2011). Forecasting energy consumption using a grey model improved by incorporating $\begin{array}{lllll}\text { genetic } & \text { programming. }\end{array}$ https://doi.org/10.1016/j.enconman.2010.06.053

Lewis, C. D. (1982). Industrial and business forecasting methods. J. Forecast, 2, 194-196.

Lin, Y., \& Lee, P. (2007). Novel high-precision grey forecasting model. Automation in Construction, 16, 771-777. https://doi.org/10.1016/j.autcon.2007.02.004

Liu, S., \& Lin, Y. (2011). Grey Systems, Springer Berlin Heidelberg, Understanding Complex Systems. Springer Berlin Heidelberg, Berlin, Heidelberg.

Lopez. (2005). The Economic Impact of Armed Conflict in Rwanda. J. Afr. Econ. 14, 586-602. https://doi.org/10.1093/jae/eji021

Maniriho, B. A. (2013). Financial Benefit-Cost Analysis of Agricultural Production in Musanze District, Rwanda. Acad. Arena, 3, 92-99.

NISR. (2015). Rwanda Poverty Profile Report 2013/2014. National Institute of Statistics of Rwanda.

NISR. (2019). Rwandan gross gomestic product fiscal year 2018_19. National Institute of Statistics of Rwanda.

NISR. (2020). National accounts and Integrated household living conditions surveys. Natl. Inst. Stat. Rwanda.

Uvin, P. (1996). Development, aid and conflict: reflections from the case of Rwanda. Research for Action Series - United Nations University, World Institute for Development Economics Research.

Wang, J., Dong, Y., Wu, J., Mu, R., \& Jiang, H. (2011). Coal production forecast and low carbon policies in China. Energy Policy, 39, 5970-5979. https://doi.org/10.1016/j.enpol.2011.06.058

Wen. (2004). Grey Systems: Modeling and Prediction. Yang's Scientific Research Institute.

World Bank. (2019). Rwanda Overview. World Bank Gr. Retrieved from https://www.worldbank.org/en/country/rwanda/overview

Wreford, A., Bayne, K., Edwards, P., \& Renwick, A. (2019). Enabling a transformation to a bioeconomy in New Zealand. Environ. Innov. Soc. Transitions, 31, 184-199. https://doi.org/10.1016/j.eist.2018.11.005

\section{Copyrights}

Copyright for this article is retained by the author(s), with first publication rights granted to the journal.

This is an open-access article distributed under the terms and conditions of the Creative Commons Attribution license (http://creativecommons.org/licenses/by/4.0/). 